\title{
Effective nasotracheal intubation using a modified transillumination technique
}

\section{[Intubation nasotrachéale efficace grâce à une technique modifiée de transillumination]}

Roberto Favaro MD, Paolo Tordiglione MD, Francesco Di Lascio MD, Donato Colagiovanni MD, Giancarla Esposito MD, Sabrina Quaranta MD, Alassandro Gasparetto MD

Purpose: Difficult intubation is a major problem in anesthesia. In case of limited mouth opening only a few intubating devices are available. Our study was designed to evaluate the effectiveness and safety of a modified transillumination technique for nasotracheal intubation (NTI).

Methods: One hundred twenty-three patients needing NTI were studied, 76 in group A: NTI with no expected intubation difficulty; and 47 in group B: limited mouth opening ( $<20 \mathrm{~mm}$ ). All intubations were performed with the Trachlight ${ }^{\mathrm{TM}}$. Patients in group $A$ were under general anesthesia while deep sedation (maintaining spontaneous breathing) was used in patients in group B. The standard transillumination technique was modified by keeping the metallic stylet in place and personalizing the length and the angle of the short arm of the $\mathrm{J}$ shaped endotracheal tube-transillumination lightwand (ETT-TL) assembly.

Results: The overall rate of success was $98.4 \%$ and $92.6 \%$ of intubations were successful on the first attempt. The average duration of intubation was $28 \mathrm{sec} \pm 15 \mathrm{sec}$. Success rate and duration of intubation were similar in both groups.

Conclusion: Modification of the technique facilitated transillumination and placement of the ETT. The simplicity and high success rate of NTI by transillumination with the TL suggest our modified technique is a valuable alternative for NTI in patients with difficult airway.

Objectif : L'intubation difficile est un problème important en anesthésie. Dans les cas d'ouverture buccale limitée, il n'existe que peu d'appareils d'intubation. Notre étude a été conçue pour évaluer l'efficacité et la sécurité d'une technique modifiée de transillumination pour l'intubation nasotrachéale (INT).

Méthode : Cent vingt-trois patients nécessitant une INT ont participé à l'étude, 76 dans le groupe A: INT sans intubation difficile appréhendée et 47 dans le groupe $B$ : ouverture buccale limitée $(<20 \mathrm{~mm})$. Toutes les intubations ont été réalisées à l'aide du Trachlight $^{\mathrm{TM}}$. Les patients du groupe $A$ ont reçu une anesthésie générale tandis qu'une sédation profonde a été utilisée pour les patients du groupe $B$. La technique ordinaire de transillumination a été modifiée en gardant en place le stylet métallique et en ajustant indi viduellement la longueur et l'angle de la branche courte de l'assemblage du tube lumineux et du tube endotrachéal en forme de J (TL-TET).

Résultats : Le taux global de succès a été de 98,4\% et 92,6\% des intubations ont été réussies au premier essai. La durée moyenne de l'intubation a été de $28 \mathrm{~s} \pm 15 \mathrm{~s}$. Le taux de succès et la durée de l'intubation ont été similaires dans les deux groupes.

Conclusion : La modification de la technique a facilité la transillumination et la mise en place du TET. La simplicité et le haut taux de succès de l'INT par transillumination avec le TL laissent croire que notre technique modifiée soit une solution de rechange valable pour l'INT de patients chez qui l'intubation est difficile.

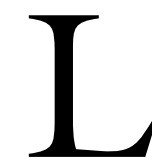

IGHTED stylet guided intubation can be a useful technique for oral and nasal intubations in both asleep and awake patients. ${ }^{1,2}$ This intubation technique has a reported success rate as high as $99 \%$ in experienced hands. ${ }^{2}$ It can be used in anticipated and unexpected difficult airways where conventional direct laryngoscopy has failed. ${ }^{3,4}$ It can be achieved as fast as conventional direct laryngoscopy by one skilled in its use. ${ }^{2-5}$ Sufficient skill is obtained after approximately ten intubations with the lighted stylet. ${ }^{6}$

Manipulation of the head and neck can be kept minimal. Patients are not required to have a wide mouth opening either for the oral or the nasotracheal approach. This technique may also be helpful in patients with an anterior larynx, scarring, or in the

From the Department of Anesthesiology and Intensive Care, University of Rome, La Sapienza, Rome, Italy. Address correspondence to: Dr. Paolo Tordiglione, Department of Anesthesiology and Intensive Care, University of Rome "La Sapienza", 837 Via Cassia, 00189 Rome, Italy. Phone: +39-0633252209; Fax: +39-064461967; E-mail: tordiglione@rocketmail.com This work was supported by the Department of Anesthesia and Intensive Care. University of Rome "La Sapienza". Accepted for publication May 28, 2001.

Revision accepted August 20, 2001. 
presence of blood since the lighted stylet has no optical viewing element. A decreased incidence and severity of sore throat, hoarseness and dysphagia has also been reported in comparison to direct laryngoscopy. ${ }^{7}$

Difficult intubations may be overcome, nowadays, with a number of devices or techniques. The alternatives are limited to only a few when we are faced with patients that have impossible direct visualization of the glottis and an inter-incisive distance of less then 25 $\mathrm{mm}$ and nasotracheal intubation (NTI) is required.

To overcome these difficulties, methods such as retrograde, flexible fibreoptic-guided and blind NTI have been developed.

Our study was designed to evaluate the effectiveness and safety of NTI performed with a flexible, semi-rigid transillumination lightwand (TL) device (Trachlight ${ }^{\mathrm{TM}}$, Laerdal Medical Corp., Armonk, NY, USA.) in patients that required NTI.

Materials and methods

\section{Device}

The TL is a flexible lightwand device composed of three parts: a reusable handle with incorporated batteries; a marked $(\mathrm{cm})$ multiple use lightwand; and a retractable aluminum stylet which allows the lightwand to be completely flexible or semi-rigid.

The device's handle allows modification of the wand's length and fastening of the endotracheal tube (ETT) to the device with a hard plastic belt system. It can be equipped with three lightwand stylets (neonatal-pediatric-adult) and allows the use of almost all sizes of ETT.

\section{Technique}

The technique adopted to perform NTI was similar to the orotracheal "J" technique already described by other authors $1,2,8$ but modified as appropriate for the naso-tracheal approach.

The modifications adopted concern the length of the short arm; the angle of the "J" and the presence of the metallic stylet at all times during the procedure, in order to maintain the shape given to the ETT.

The short arm of the "J" was given the length of the patient's gonal angle-mandibular symphysis distance (Figure 1). Normally, this distance is slightly greater than the length of the hard palate (nasal vestibulum-upper pharynx). Thus, when the ETT together with the stylet were introduced in the nose up to the angle of the "J", we were sure that the tip of the ETT was free from any anatomical structure.

The angle of the "J" impressed to the ETT and the lightwand ranged from 80 to 100 and depended on the patient's mandibular symphysis-thyroidal distance.
In order to have the tip of the ETT orientated optimally once in the patient's pharynx, an angle of 80 was used when the distance was $<55 \mathrm{~mm}$, of 90 for distances ranging from 55 to $75 \mathrm{~mm}$, and 100 for distances $>75 \mathrm{~mm}$. For pediatric patients an angle of 80 was used in all cases.

Great care was given to the preparation of the device and the patient's upper airways for a smoother and less traumatic technique in order to avoid epistaxis or other lesions. We lubricated carefully the ETT, the lightwand and its semi-rigid metallic stylet. With the patient's head and neck in a neutral position we cautiously inserted the ETT through the nose keeping the TL's handle to the side and perpendicular to the patient's profile. Once passed the nasal cavity we rotated the device towards the patient's feet (90) while simultaneously lifting (90) the handle, taking care not to modify the shape previously given to the ETT. At this stage, upward traction was applied to the jaw (to free the posterior pharynx from the epiglottis), and we positioned the ETT in the larynx. Subsequent manoeuvers comprised back and forward manoeuvering ("rocking chair" movement) and lateral manoeuvering until a bright luminescence could be seen in the neck. At this stage, with the ETT placed correctly in the larynx, the metallic stylet was retracted slightly and the now pliable ETT slowly inserted in the trachea. After seeing the light disappear below the sternal notch, the TL was detached from the ETT and withdrawn, taking care to keep the ETT in place.

If the above procedure did not allow transillumination of the larynx within $60 \mathrm{sec}$, the intubating device was withdrawn, and the patient ventilated by mask with pure oxygen for $60 \mathrm{sec}$. At this stage, the angle of the "J" would be modified and a second attempt made. A total of three attempts were allowed before considering the technique had failed. Wire-reinforced ETT were used for all intubations.

\section{Study protocol}

The study was approved by the Ethics Committee and informed consent was obtained from each of the 123 patients studied. The first group included 76 patients, requiring NTI, candidates for oral/maxillo-facial surgery without expected or past history of difficult intubation (group A). This group was enrolled to evaluate the safety, efficacy and actual rate of success of our modified transillumination technique. The second group included 47 patients who required NTI for surgical correction of temporo-mandibular joint ankylosis. In this group, all patients had an inter-incisive distance of $20 \mathrm{~mm}$ or less (Figure 2), rendering traditional laryngoscopy impossible (group B). 
Criteria of exclusion from the study were: patients with physical status ASA III-IV, presence of coronary heart disease, cerebro-vascular abnormalities, respiratory tract disease, and a known risk of regurgitation-aspiration. No morbidly obese patients were evaluated.

Patient's upper airways were prepared with $10 \%$ lidocaine spray in both nostrils and lubricant gel was placed on the cuff of the ETT.

We always used a wire-reinforced ETT which allowed us to have an extremely soft and smooth material together with a greater safety during the surgical manoeuvers (frequent cervical mobilization). The tube diameter was kept as small as possible to allow ventilation while reducing the risk of airway trauma as much as possible.

Patients were monitored routinely with echocardiogram; $\mathrm{Sp}_{2} ; \mathrm{EtCO}_{2}$, and non-invasive blood pressure. Premedication consisted of $0.05 \mathrm{mg} \cdot \mathrm{kg}^{-1}$ midazolam $i v$. Patients were preoxygenated for three minutes and anesthesia induced with propofol, alfentanil, and rocuronium iv.

Patients in group A received: propofol $2 \mathrm{mg} \cdot \mathrm{kg}^{-1}$, alfentanil $20 \mu \mathrm{g} \cdot \mathrm{kg}^{-1}$, rocuronium $0.9 \mathrm{mg} \cdot \mathrm{kg}^{-1}$ and mask ventilation $\left(100 \% \mathrm{O}_{2}\right)$.

Patients in group B received: propofol $1 \mathrm{mg} \cdot \mathrm{kg}^{-1}$ and alfentanil $20 \mu \mathrm{g} \cdot \mathrm{kg}^{-1} i \mathrm{v}$. Drugs were administered slow ly to maintain spontaneous ventilation. Neuromuscular blocking agent was administrated, if necessary, only after intubation was completed.

For all patients anesthesia was maintained with a continuous infusion of propofol $4-6 \mathrm{mg} \cdot \mathrm{kg}^{-1} \cdot \mathrm{hr}^{-1}$, alfentanil as needed, and $\mathrm{N}_{2} \mathrm{O} / \mathrm{O}_{2}(60 / 40 \%)$.

All intubations were performed by two anesthesiologists skilled with the use of the transillumination technique for orotracheal intubation. Both had performed 50 to 70 intubations with the TL.

\section{The following data were recorded for each patient}

a) Duration of intubation

1) Insertion time (IT): time to introduce the tube through the nose into the upper pharynx

2) ETT placement time (ET): time needed to position the ETT in the trachea

3) Total time (TT): the sum of the previous two (IT + ET)

b) The number of attempts, failures and perioperative complications

\section{Statistics}

The data are reported as means \pm SD. The Student $t$ test for unpaired data was used to compare the duration of intubation between the two groups. Categorical data were analyzed using the Chi-square contingency table. Differences were considered statistically significant if $P<0.05$.
Results

The demographic characteristics of the two groups are shown in Table I and were not different statistically.

The overall rate of success of NTI by transillumination with the TL was $98.4 \%$, with $91 \%$ of patients intubated at the first attempt (Table II).

Duration of intubation and the complications related to NTI are summarized in Table III.

Nose bleeding was considered present when blood could be seen at the nose. It was considered minor if it did not influence the intubating procedure or did not require nasal packing.

\section{Group A}

NTI with the TL was successful in $98.7 \%(75 / 76)$ of patients. All patients were intubated on the first or second attempt. None required a third attempt (Table II).

Only one patient could not be intubated with this technique (1.3\%) and was intubated successfully by conventional laryngoscopy.

The average duration of intubation was of $27 \mathrm{sec} \pm$ $16 \sec$ (Table III).

TABLE I Demographics of patients studied

\begin{tabular}{|c|c|c|}
\hline \multicolumn{2}{|c|}{$\begin{array}{l}\text { Group A } \\
\text { No difficulty expected } \\
(n=76)\end{array}$} & \multirow{2}{*}{$\begin{array}{l}\text { Group B } \\
\text { Difficulty expected } \\
(n=47)\end{array}$} \\
\hline Male / Female & $39 / 37$ & \\
\hline Weight (kg) & $66.51 \pm 12.80$ & $63.73 \pm 12.36$ \\
\hline Age (yr) & $34.59 \pm 17.18$ & $31.29 \pm 18.33$ \\
\hline
\end{tabular}

TABLE II Success rates in groups A and B

\begin{tabular}{lll}
\hline Group $A(n=76)$ & & \\
Success at $1^{\text {st }}$ attempt & $92.1 \%$ & $(70 \mathrm{pt})$ \\
Success at $2^{\text {nd }}$ attempt & $6.6 \%$ & $(5 \mathrm{pt})$ \\
Failed & $1.3 \%$ & $(1 \mathrm{pt})$ \\
Group $B(n=47)$ & & \\
Success at $1^{\text {st }}$ attempt & $89.4 \%$ & $(42 \mathrm{pt})$ \\
Success at $2^{\text {nd }}$ attempt & $4.25 \%$ & $(2 \mathrm{pt})$ \\
Success at $3^{\text {rd }}$ attempt & $4.25 \%$ & $(2 \mathrm{pt})$ \\
Failed & $2.10 \%$ & $(1 \mathrm{pt})$ \\
\hline
\end{tabular}

TABLE III Duration of intubation and complication rate

\begin{tabular}{lll}
\hline & Group A & Group B \\
\hline Number of patients & 76 & 47 \\
Insertion time (IT) & $8.9 ” \pm 6.5 ”$ & $8.8 ” \pm 6.3 ”$ \\
ETT placement time (ET) & $18.4 " \pm 13.6 ”$ & $20.1 " \pm 14.5 ”$ \\
Total time (TT) & $27.3 " \pm 15.6 ”$ & $28.9 " \pm 15.9 ”$ \\
Pain on swallowing /sore & $33 / 75(44 \%)$ & $22 / 46(47.8 \%)$ \\
throat and hoarseness & & \\
Minor epistaxis & $4 / 75(5.3 \%)$ & $2 / 46(4.35 \%)$ \\
\hline
\end{tabular}




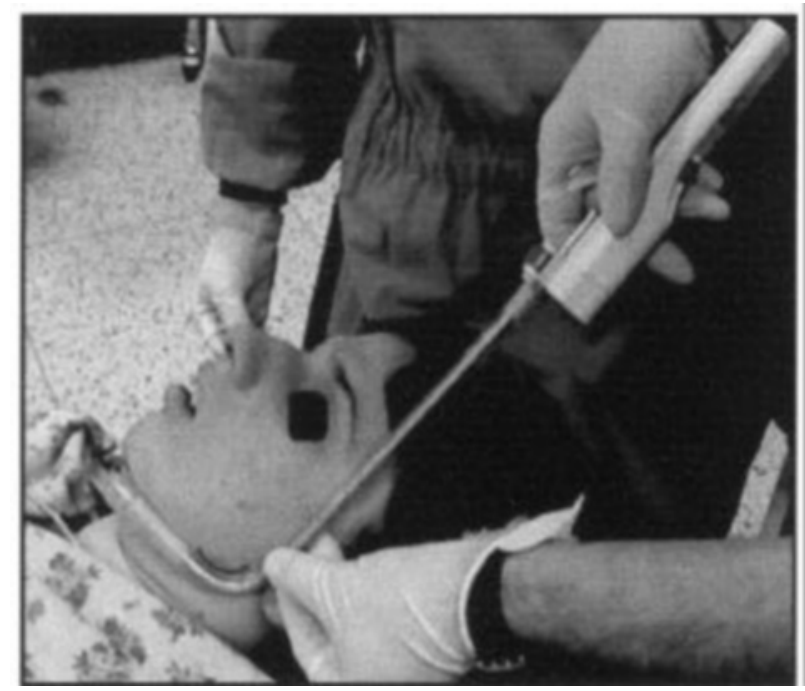

FIGURE 1 The short arm of the "J" is equal to the gonal anglesymphysis distance.

Nasal bleeding was noted in $5.3 \%$ of the patients, while complaints of sore throat and/or hoarseness were recorded in $44 \%$ of patients.

\section{Group B}

Patients were intubated successfully on the first, second and third attempts in $89.4 \%, 4.25 \%$ and $4.25 \%$ of cases respectively.

Only one patient $(2.10 \%)$ could not be intubated with the TL, and required intubation with a fibreoptic endoscope. Transillumination could be obtained but the ETT would not proceed in the trachea after withdrawing the metallic stylet.

The mean duration of NTI was $29 \mathrm{sec} \pm 16 \mathrm{sec}$ (Table III).

Duration of intubation (insertion, placement and total) was not statistically different $(P>0.05)$ between groups. Minor nose bleeding was observed in $4.35 \%$ of patients. Postoperative sore throat and hoarseness were observed in $47.8 \%(22 / 46)$ of patients.

Discussion

Intubation with the TL is a reliable alternative technique for difficult orotracheal intubation. ${ }^{2}$

The high rate of success observed in the present study $(98.4 \%)$, allows us to recommend transillumination in patients with a limited mouth opening who require NTI, as an alternative to the traditional techniques already mentioned.

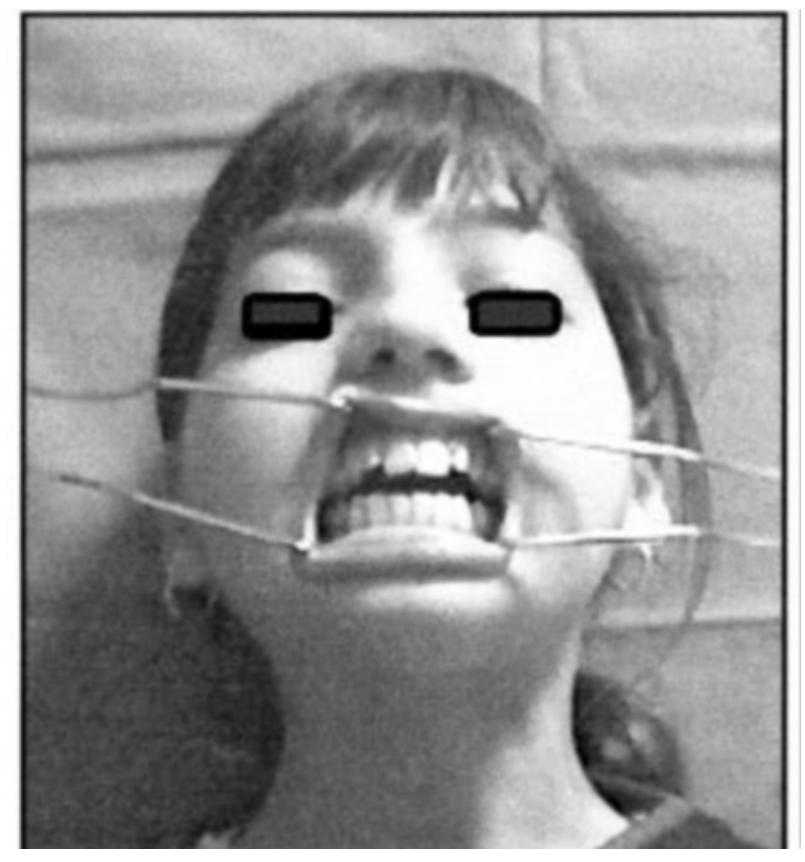

FIGURE 2 Temporo-mandibular joint ankylosis: maximal mouth opening.

Failure to intubate the patient in group A was probably due to inexperience in NTI with the TL and increased prudence since the technique was not required. The failure observed in group B was subsequently managed with a fibreoptic endoscope and proved difficult because of a large epiglottis and lateral deviation of the larynx.

A few modifications are essential to achieve a high rate of success with this technique. We keep the metallic stylet in place at all times to maintain the shape of the ETT and to facilitate manoeuvering of the ETT into the larynx.

It is also essential to carefully lubricate the device and ETT and to prepare the patient's upper airways adequately. The shape of the ETT together with the TL should be personalized in order to achieve a smooth, rapid and least traumatic intubation procedure. Correct personalization requires adjusting both the length of the short arm and the angle of the "J" formed by the ETT and the stylet.

The low incidence of intraoperative complications (minor nasal bleeding) suggests that the precautions adopted were adequate to prevent trauma. On the other hand, the high incidence of postoperative morbidity such as sore throat, pain on swallowing and hoarseness compared with published data ${ }^{7}$ is, in our 


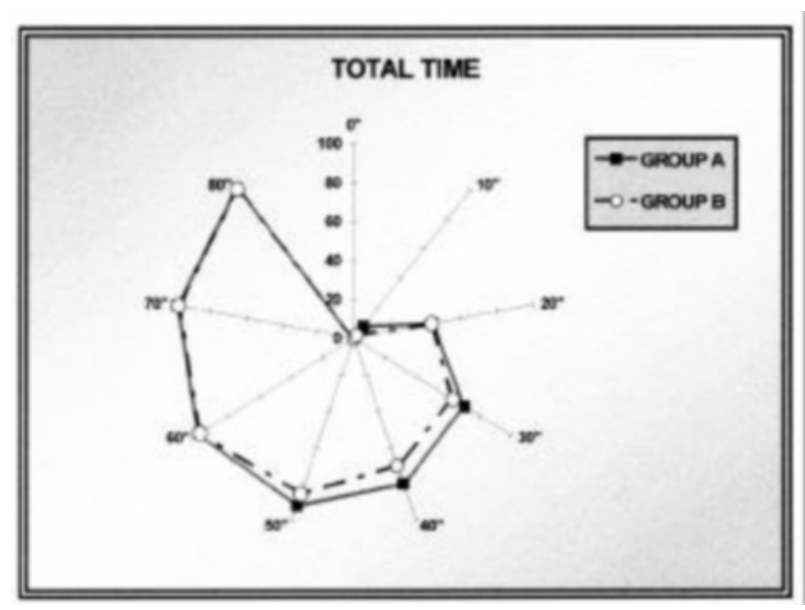

FIGURE 3 Total time/percentage of successful nasotracheal intubation by transillumination in groups A and B.

opinion, related more to the type of surgery (requiring frequent mobilization of the head and neck) than to the actual intubation technique.

As shown in Figure 3, over $60 \%$ of patients were intubated successfully within $30 \mathrm{sec}$ and more than $95 \%$ within $60 \mathrm{sec}$. Overall, TT averaged $28 \mathrm{sec} \pm 15$ sec, which is quite acceptable considering it includes the time needed to introduce the ETT carefully through the nostril and the rhinopharynx.

Once passed the nasal cavity, time to position the ETT in the trachea (similar to the time required for orotracheal intubation with the TL), was $19 \mathrm{sec} \pm 14$ sec and is comparable with that reported in literature. ${ }^{3}$

The relatively small standard deviation of duration of intubation using this technique $( \pm 14 \mathrm{sec})$, points to its efficacy, in comparison with the great fluctuations in duration reported for the blind technique..$^{8-10}$

In summary, our data show that the transillumination approach for NTI is fast, effective and does not require extra time to place the ETT in the trachea. We believe that the simplicity, the efficacy and the safety of NTI by transillumination with the TL make this a useful and readily available alternative for NTI in patients with difficult airways.

\section{References}

1 Hung OR, Stewart RD. Lightwand intubation: I - A new lightwand device. Can J Anaesth 1995; 42: 820-5.

2 Hung OR, Pytka S, Morris I, et al. Clinical trial of a new lightwand device (Trachlight) to intubate the trachea. Anesthesiology 1995; 83: 509-14.
3 Hung OR, Pytka S, Morris I, Murphy M, Stewart RD. Lightwand intubation: II - Clinical trial of a new lightwand for tracheal intubation in patient with difficult airways. Can J Anaesth 1995; 42: 826-30.

4 Holzman RS, Nargozian CD, Florence FB. Lightwand intubation in children with abnormal upper airways. Anesthesiology 1988; 69: 784-7.

5 Ellis DG, Jakymec A, Kaplan RM, et al. Guided orotracheal intubation in the operating room using a lighted stylet: a comparison with direct laryngoscopic technique. Anesthesiology 1986; 64: 823-6.

6 Langeron $O$, Lenfant F, Aubrun F, Riou B, Coriat P. Evaluation de l'aprentissage d'un nouveau guide lumineux (Trachlight ${ }^{\mathrm{TM}}$ ) pour l'intubation trachéale. Ann Fr Anesth Rean im 1997; 16: 229-33.

7 Friedman PG, Rosenberg MK, Lebenbom-Mansour M. A comparison of light wand and suspension laryngoscopic intubation techniques in outpatients. Anesth Analg 1997; 85: 578-82.

8 Ellis DG, Stewart RD, Kaplan RM, Jakymec A, Freeman JA, Bleyaert $A$ Success rates of blind orotracheal intubation using a transillumination technique with a lighted stylet. Ann Emerg Med 1986; 15: 138-42.

9 Hyrabayashi $\Upsilon$, Hiruta M, Kawakami T, et al. Effects of lightwand (Trachlight) compared with direct laryngoscopy on circulatory responses to tracheal intubation. Br J Anaesth 1998; 81: 253-5.

10 Verdile VP, Chiang J-L, Bedger R, Stewart RD, Kaplan $R$, Paris $P M$. Nasotracheal intubation using a flexible lighted stylet. Ann Em Med 1990 19: 506-10. 